تصميم وسيلة مقترحة لقياس القوة الد فعية.

محمد على عبد المجيد المقطف

قسم تدريب مسابقات الميدان و المضماركلية التربية الرياضية للبنين - جامعة الإسكندرية - جمهورية مصر العربية.

المقدمة ومشكلة البحث

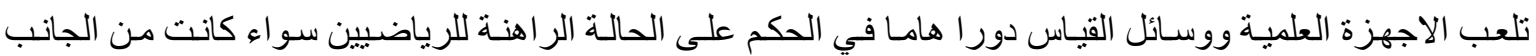

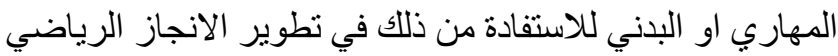

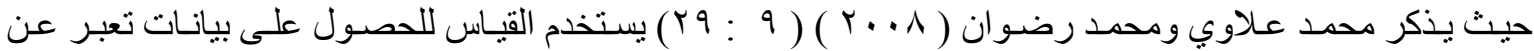
مستوى الافر اد وان التعبير الكمي عن الخصائص المميزة يثير الى ما يمتلكه الفرد بالنسبة لسمة او صفة من الصفئ الصفات

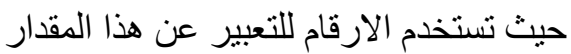

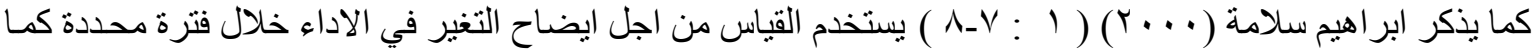
يمكن استخدام وسائل القياس بشكل فردي طبقا لمستوى الاداء لبعض الصفات المميزة

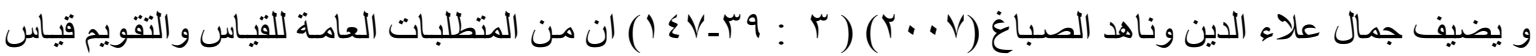

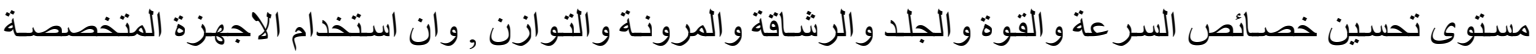

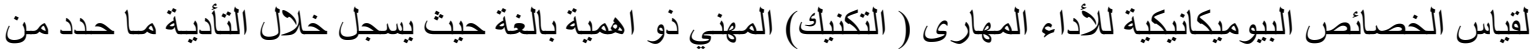

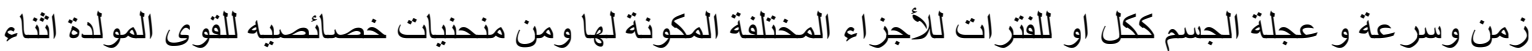

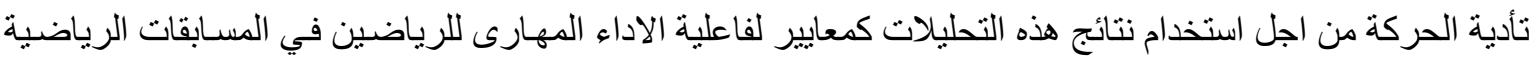

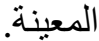

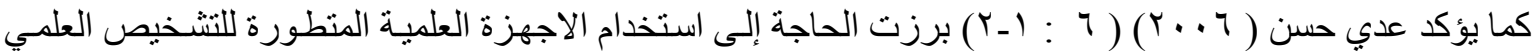

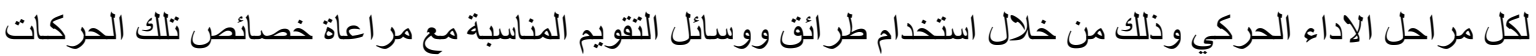

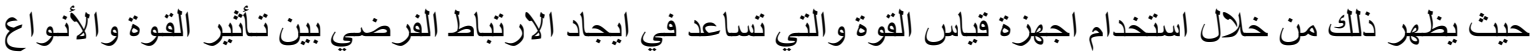

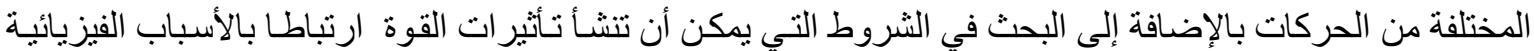
للحركة.

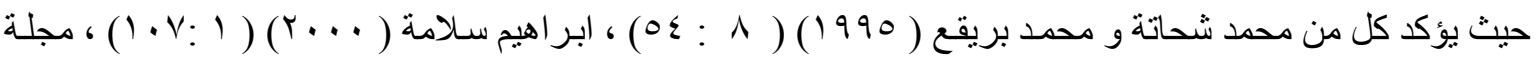

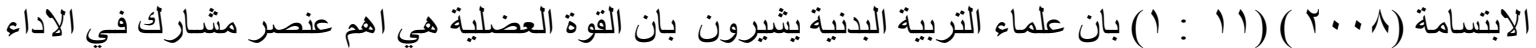

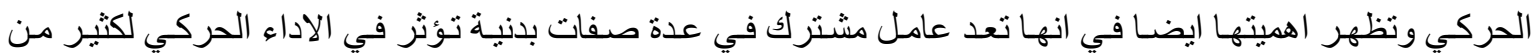
الانشطة الرياضية حيث تعتبر عنصر اساسي لإحداث الطاقة الحركية

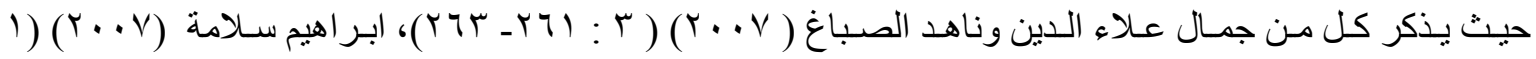
: A • ( ) بانة يمكن تفسير القوة العضلية من خلال امكانية قياسها من خلال ما يعرف بالقوة القصوى

- نظر التعلق مستويات الانجاز و النتائج المحققة في جميع انواع الانشطة الرياضية بدرجة نمو خصسائص القوة

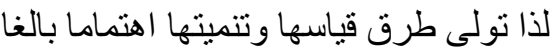
- - تمثل القيم اللحظية للقوة في أي من لحظات الحركة وخاصة القوة القصوى احد مؤشر ات قياس خصائص القوة

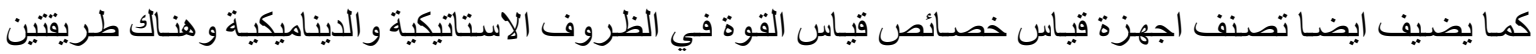
لتسجيل خصائص القوة 1 - بدون استخدام اجهزة 
r. باستخدام اجهزة قياس اما تقبس تشوه او تغير شكل الجسم الذى نطبق عليـة القوة او مجموعـة اجهزة تقيس

عجلة حركة الجسم المتحرك

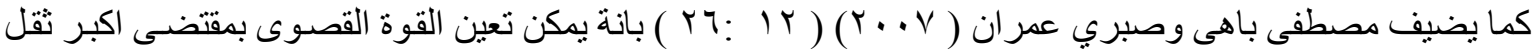

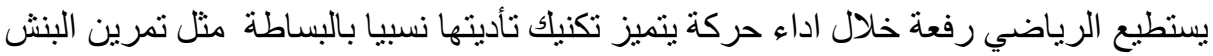

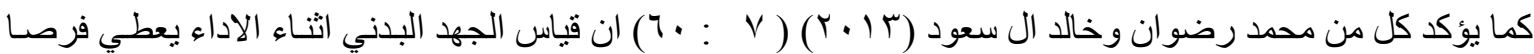

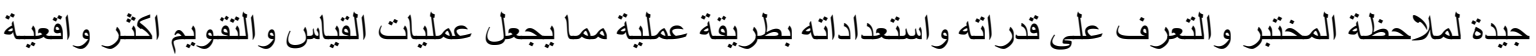
و اكثر صدقا

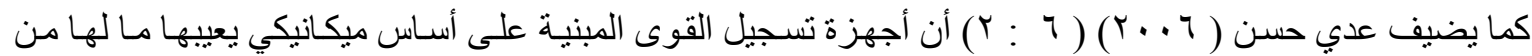

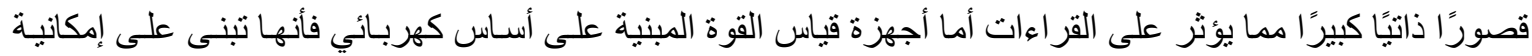
تحويل التأثثر الميكانيكي للقوة إلى قيمـة كهربائية وبمسـاعدة أجهزة القياس المختلفة يمكن تحقيق هذا التحول بالقيمـة المقاسة

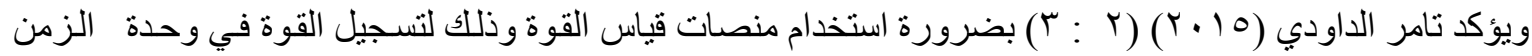
لتقنين القوة المستخدمة في الاداء الرياضي (بردي

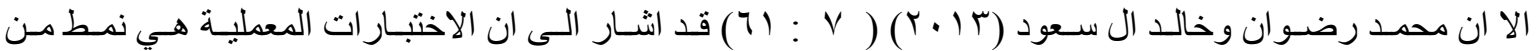

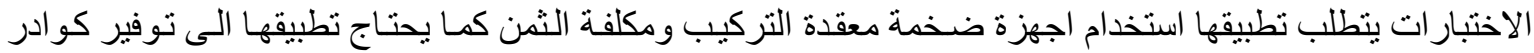

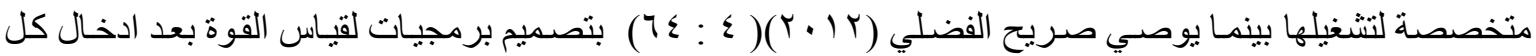
المتغير ات الخاصة بها لسهولة استخدامها من قبل المدرب وبنس وبشكل مبانشر

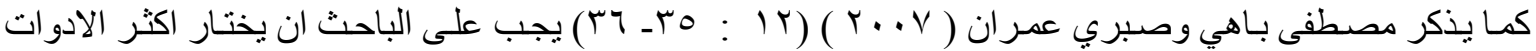

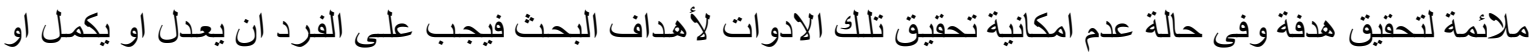

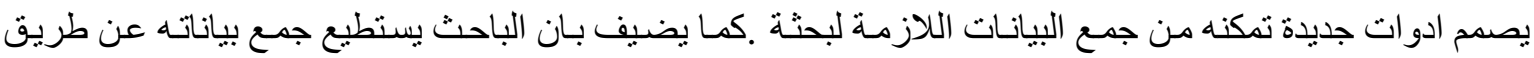
استخدام الطرق الاتية :

\section{- -}

و علية فقد حاول الباحث ابتكار خدمات دعم علمية لإمكانية الوصول الى موارد جديدة للاستمر ار في تقديم افكار جديدة

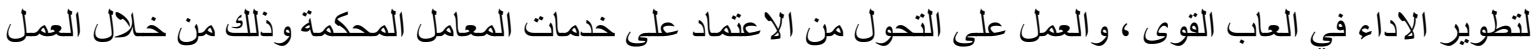

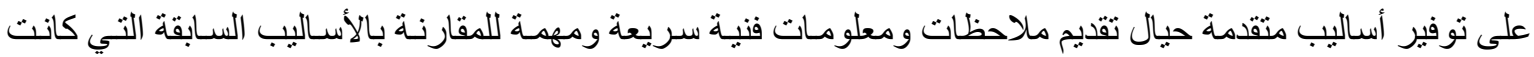

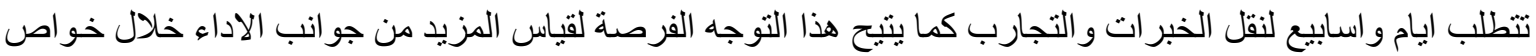

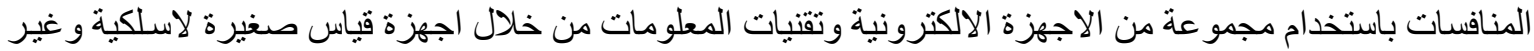

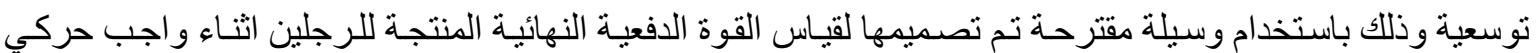

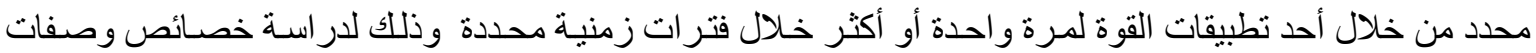

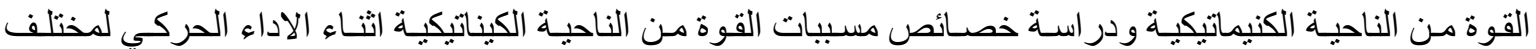

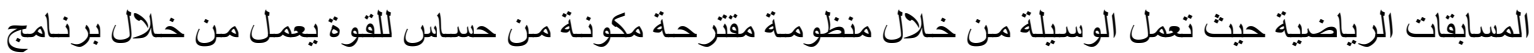

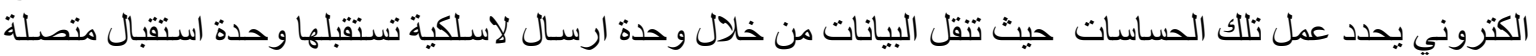
بالحاسب الالـي حيـ تعـرض البيانـات مـن خـلال برنـامج خـاص كمـا يمكن تسـيل مقـادير القوة مـن خـلال شـريحة الكترونية memory card موضو عة بالوسيلة المقترحة . 
- هي نوع من انو اع الدفوع و هي القوة الناتجة من التصادم اللحظي لجسمين لفترة زمنية قصيرة جدا

هدف البحث:

- التعرف على مدى امكانية استخدام الوسيلة المقترحة لقياس عنصر القوة الدفعية المنتجة للرجلين .

تساؤل البحث:

- هل يمكن استخدام الوسيلة المقترحة لقياس عنصر القوة الدفعية المنتجة للرجلين.

واجبات البحث : n

-

- اخضاع الوسيلة للفحص و المعايرة العلمية

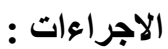

- المنهج المستخلم : المنهج التجريبي

ـ المجال المكاني : (معمل البيوميكانيك - صالة اللياقة البدنية - مضمار العـاب القوى) كليـة التربيـة الرياضية

للبنين - جامعة الاسكندرية

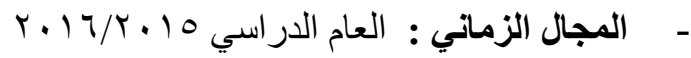

- المجال البشري : ناشئين مركز شباب أبوقير الرياضي

عينة البحث : اختبرت العينة بالطريقة العمدية حيث طبق البحث على عدد V من ناشئين مركز شباب أبوقير الرياضي هي

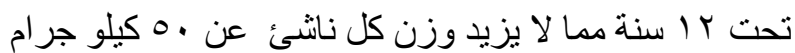
مواصفات عينة البحث

جدول (1)

يوضتح الاسم والنوع والسن والوزن لأفراد عينة البحث

\begin{tabular}{|c|c|c|c|c|}
\hline الوزن كجم & السن بالسنة & النوع & الاسم & م \\
\hline ro & Ir & ذكر & احمد تركي & 1 \\
\hline$\leqslant 1$ & Ir & ذكر & يوسف محمد & r \\
\hline$r \Lambda$ & Ir & ذكر & وليد فوزي & $r$ \\
\hline$\leqslant 9$ & Ir & ذكر & احمد عبد النبي & $\varepsilon$ \\
\hline$m$ & ir & ذكر & مصطفى خميس & $\bullet$ \\
\hline$\leq 9$ & Ir & ذكر & احمد جابر & 7 \\
\hline ro & 11 & انثى & ندى محمد & $\mathrm{v}$ \\
\hline
\end{tabular}

قياسات البحث :

اولا القياسات الانثروبومترية:

- - - قياس الطول الكلي ( سم ) -

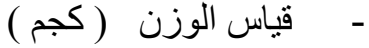

ثانيا قياسات : المحك الخارجي 
1. قياسات القوة الدفعية باستخدام جهاز قياس منصة القوة

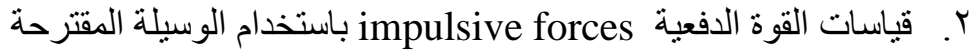

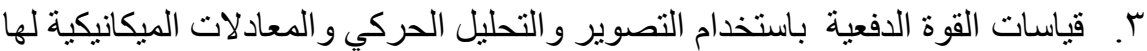
وذلك بأداء (قياس أعلى قيمة قوة منتجـة من الحجلة للأمسام ـ قبـاس أعلى قيمـة قوة منتجة لعدد ثنلاث ارتقاءات راسية متكررة على قدم واحدة )

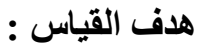

الحصول على أعلى قيمة قوة منتجة لكل من ( الحجلة للأمام ـ لعدد ثلاث ارتقاءات راسية متكررة على قدم واحدة ) . شكل (1) - (1) (1)

نماذج من قياسات القوة الدفعية - برنامج التحليل الحركي ـ تجهيز ادوات الوسيلة المقترحة

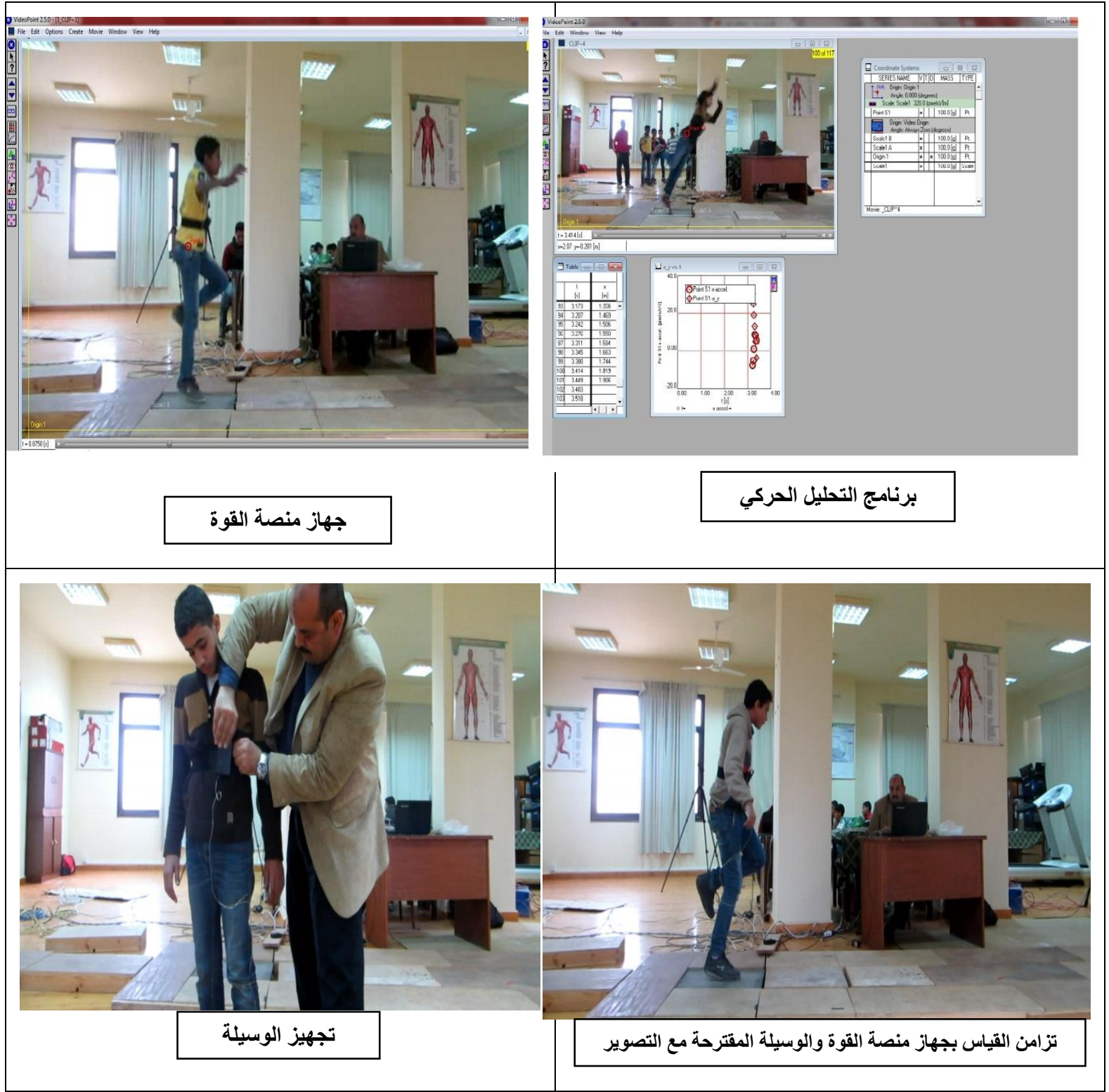




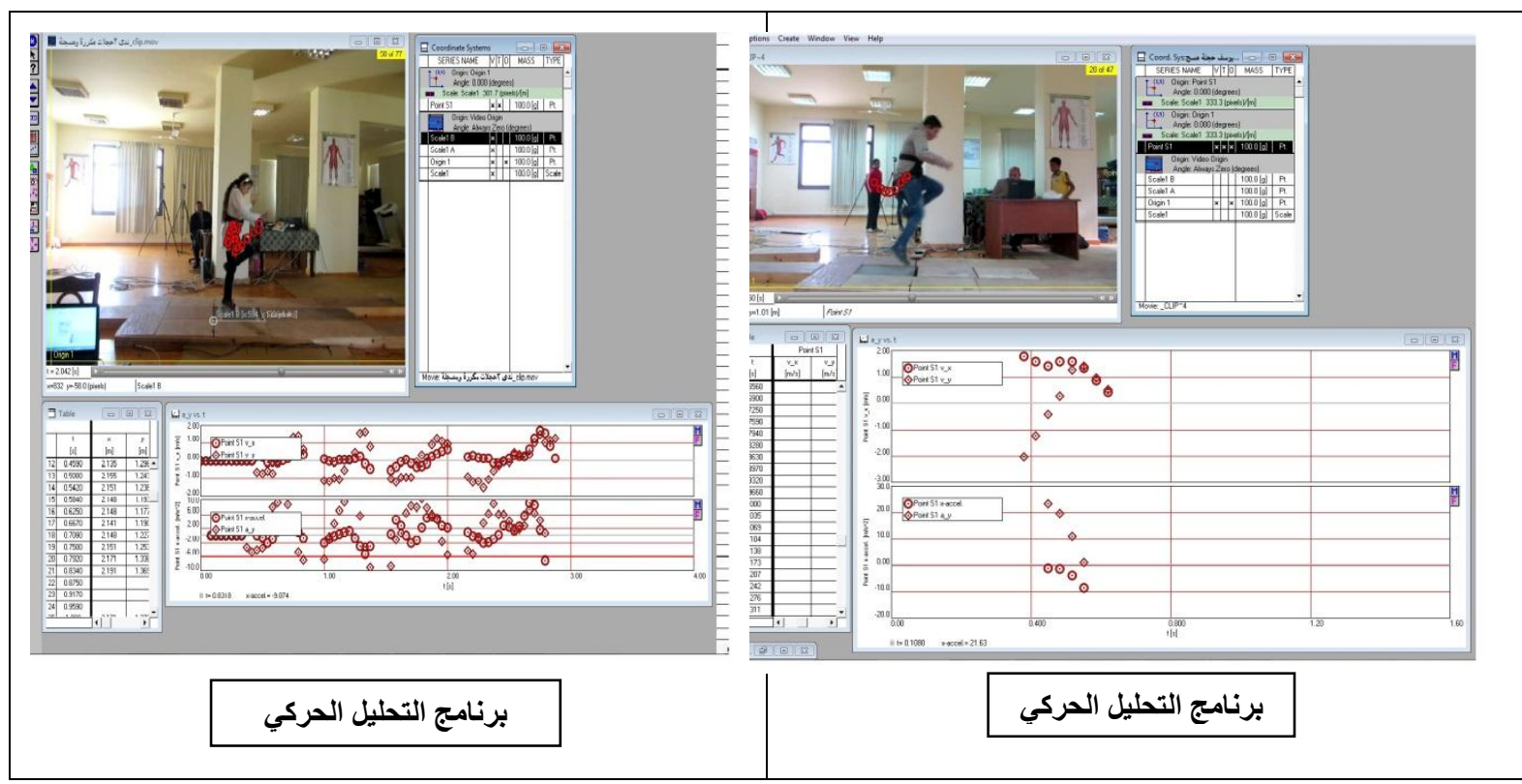

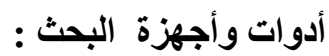

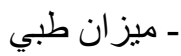

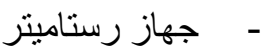

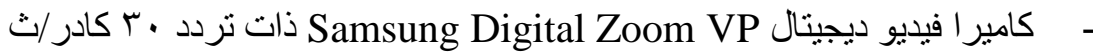

- التحليل الحركي البيوميكانيكي ببرنامج فيديو بوينت ه.ب (Video Point 2.5)

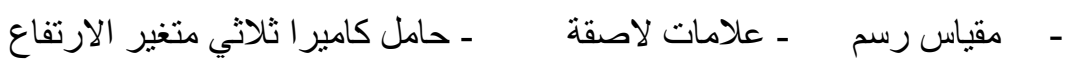

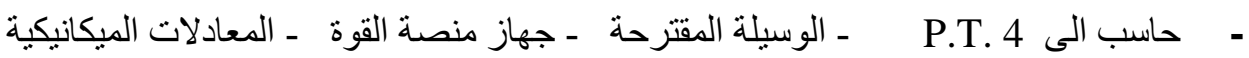

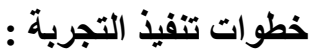

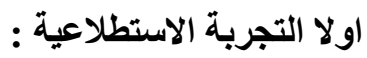

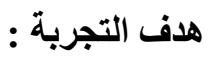

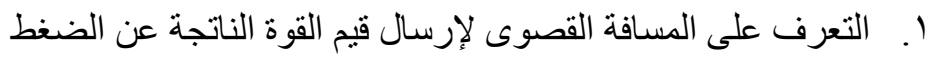

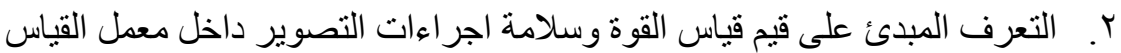

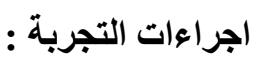

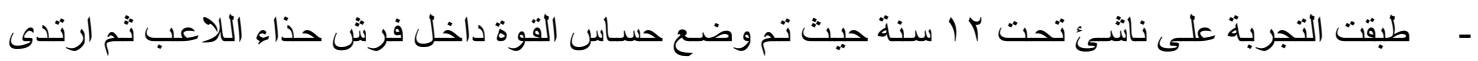

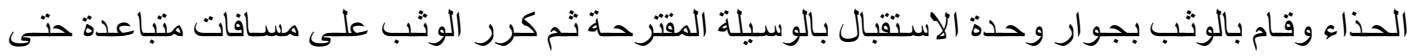

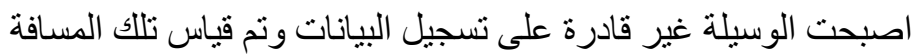

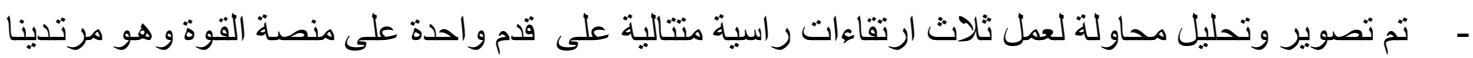

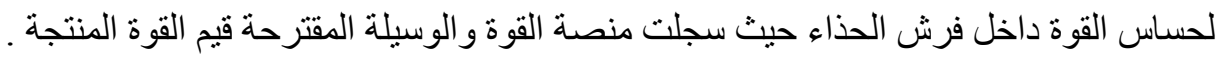

نتائج التجربة :

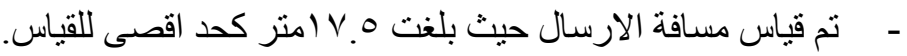

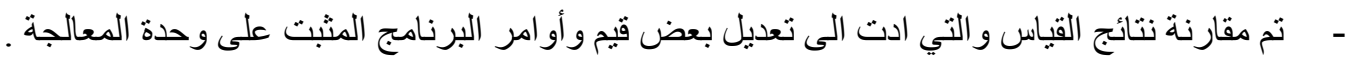


- تم تعديل مكان التصوير للاختيار انسب مكان لوضع الكاميرات .

ثانيا تصميم الوسيلة المقترحة :

تتكون الوسيلة المقترحة من ثلاث وحدات و هما كالاتي : شكل رقم (r) الوحدة الاولى وحدة قياس القوة الدفعية والتي تتكون من الاتي :

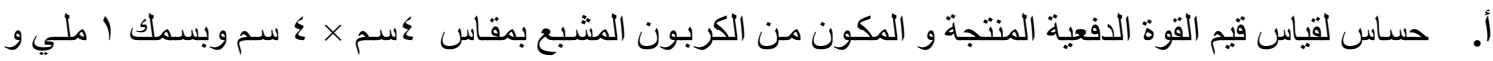

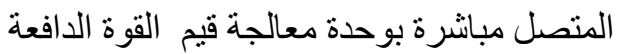
ب. الحد الاقصى لقياس الوسيلة .... بنيوتن .

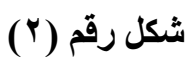

حساس قياس قيم القوة الافعية

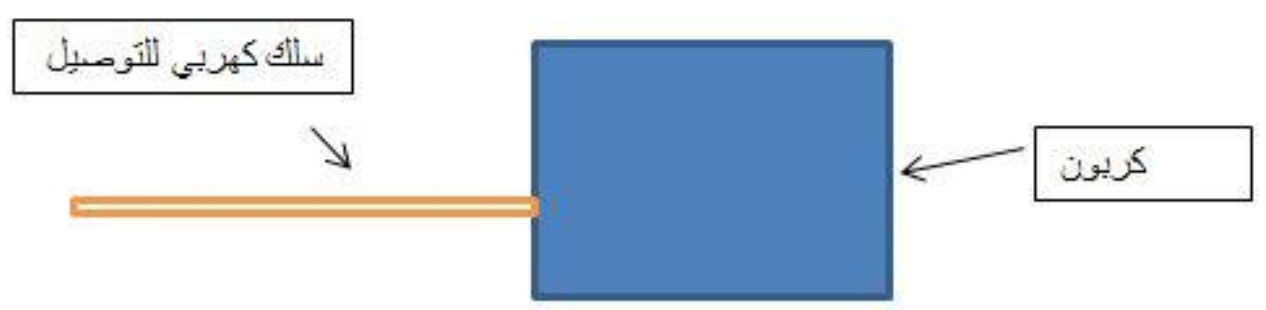

الوحدة الثانية وحدة معالجة قيم القوة الدفعية المقاسة و التي تتكون من الاتي: شكل ( بام)

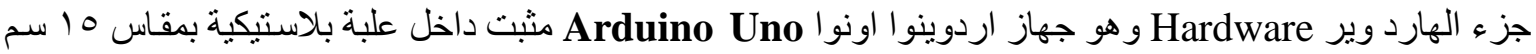

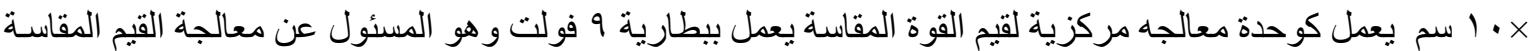
وارسالها خلال ثلاث طرق اختيارية مختلفة الى الحاسب الالي أما :

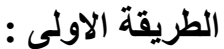

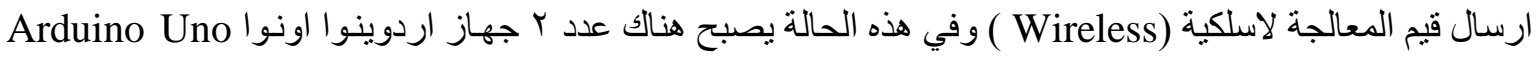

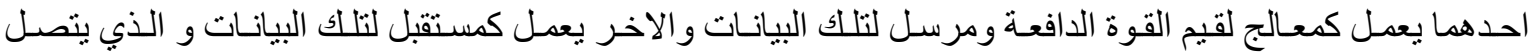
بSB بالحاسب الالي عن طريق مدخل

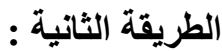

ارسال قيم القوة الدفعية المعالجة عن طريق تسجيل تلك القيم على شريحة الكترونية خارجية memory card (فلاشـها

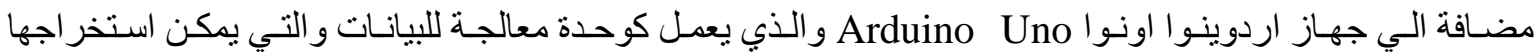
و وايصالها بالحاسب الالي لاستخر اج البيانات المسجلة عليها .

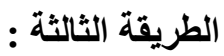


الارسال المباشر لقيم القوة الدفعية التي تم معالجتها من جهاز اردوينوا اونو الإل Arduino Uno الى الحاسب الالي عن

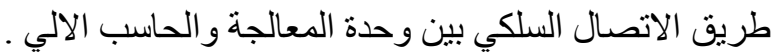
الوحدة الثالثة وحدة السوفت وير Software و التي تتكون من الاتي:

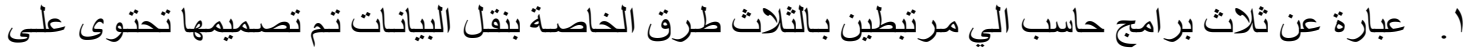

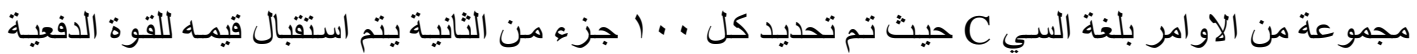

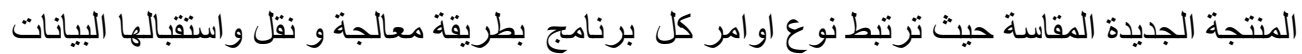

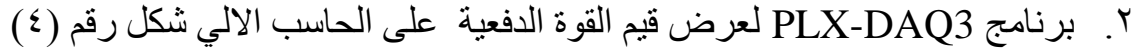

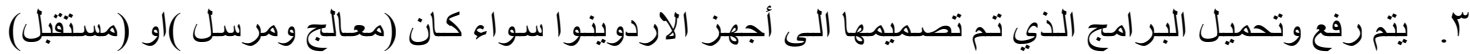
للبيانات عن طريق الحاسب الاليج التي

\section{شكل رقم (r)}

وحدة معالجة قيم القوة المنتجة اردوينوا اونو Arduino Uno ـ شكل رقم ( ؛ ) واجهة برنامج PLX-DAQ3 لعرض البيانات

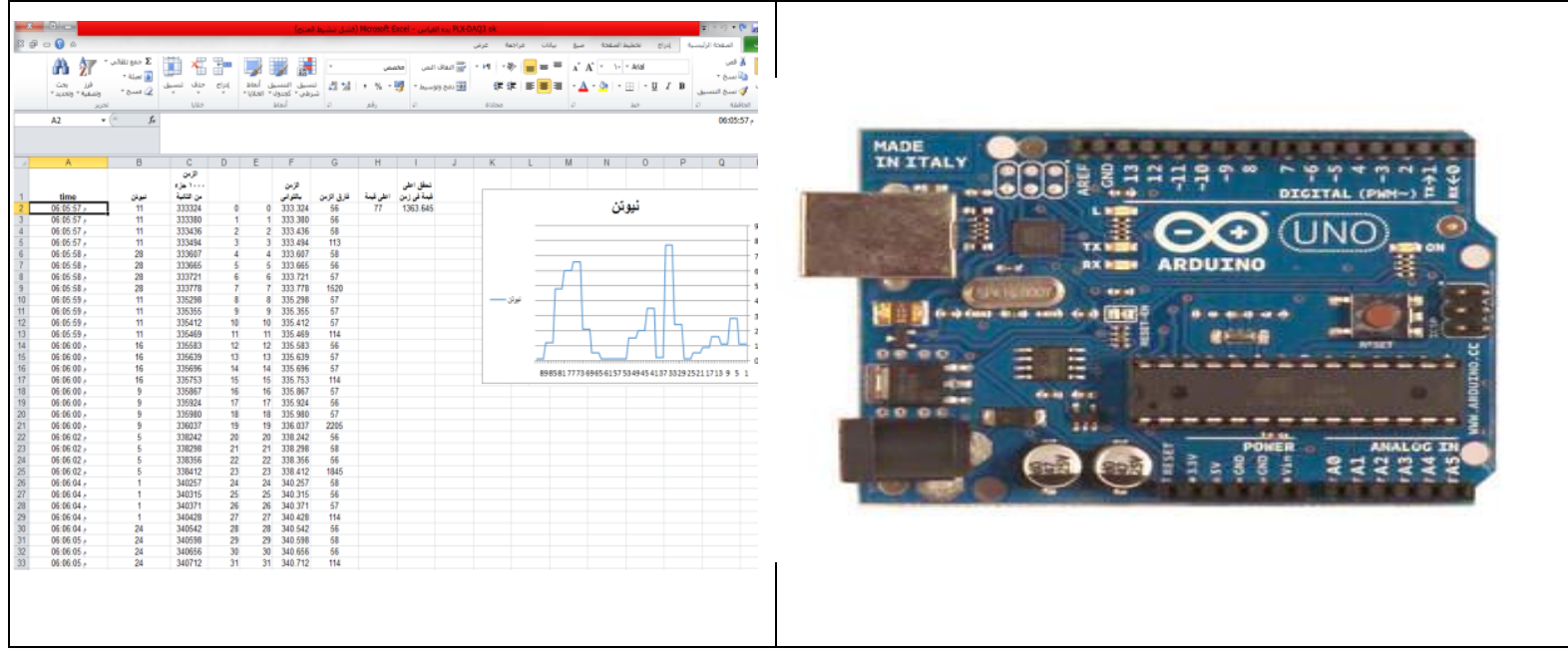

الاساس العلمي الميكانيكي للوسيلة المقترحة :

أ. في حالـة حدوث القوة الضـاغطة على حسـاس القوة و المكون من حبيبـات الكربون المشبع تتغير مقاومـات

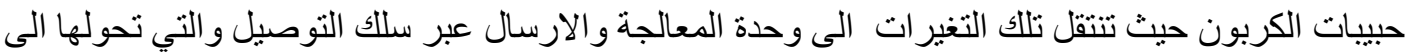

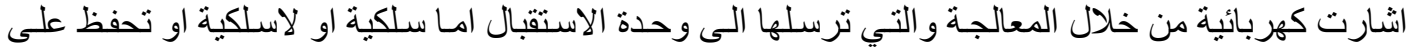

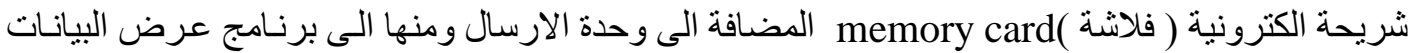
- PLX DAQ3

طريقة استخدام الوسيلة المقترحة : في حالة قياس القوة الدفعية من خلال ارتكاز احد القدمين اوكلاهما معا : ا. . وضع حساسات قيـاس القوة الدفعيـة المتصلة بوحدة الارسـال اسفل الثلث الامـامي لكل قدم من خلال تثبيت الحساس بفرش اضافي للحذاء ثم ارتداء الحذاء . 
r. توصيل وحدة الاستقبال بالحاسب الالي في حالة الارسال بدون سللك (لاسلكي) او توصيل وحدة الارسـال

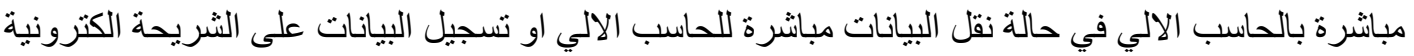

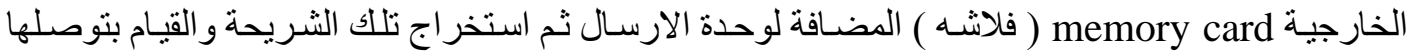

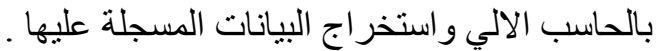

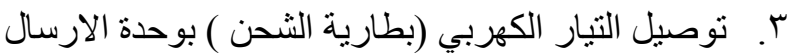
ع. . فتح برنامج عرض البيانات PLX-DAQ3 بالحاسب الالي ثم الضغط على مفتاح التشغيل لبدء التسجيل

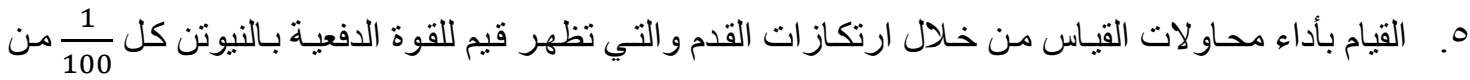

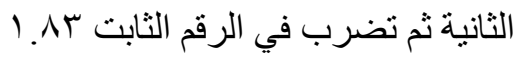

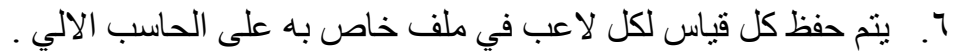

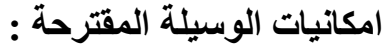

ا. . الوسيلة صغيرة الحجم تعتمد على التقام التكنولوجي في اسلوب القياس ومعالجة البيانات r. بلة تكلفة تصنيع الوسيلة المقترحة

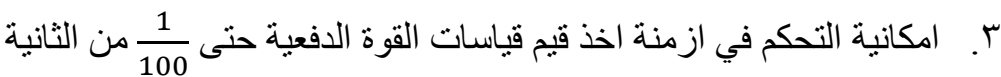

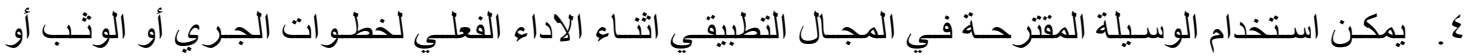

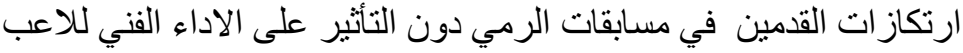
○. استخدام الوسيلة المقترحة مع التصوير البيوميكانيكي للأداء الفعلي امكن الاستخر اج الفواء الفوري لقيم القوة الدافعة

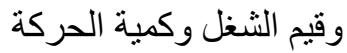

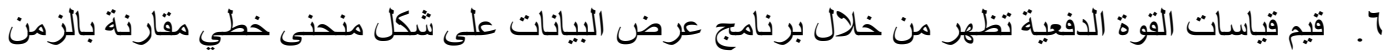

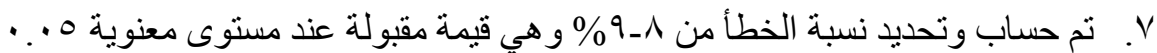

\section{الواجبات المحدة للقياس وفق الترتيب الاتي}

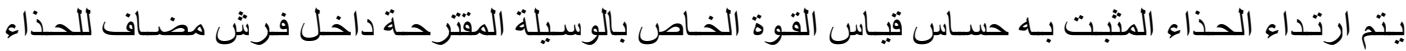

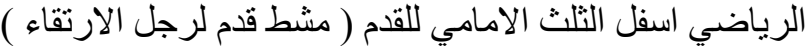

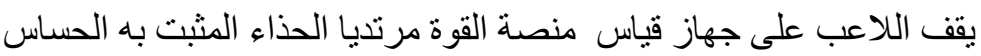

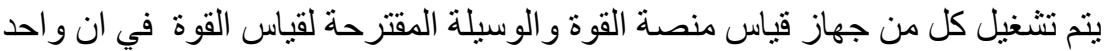

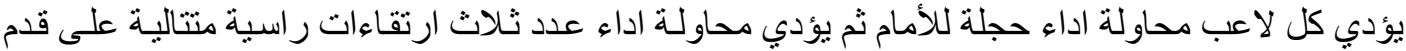

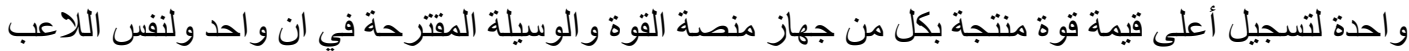

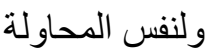

ينم التصوير و التحليل الميكانيكي لجميع محاو لات القياسات لاستخر اج متغيرات (العجلة ـ الكتلة ـ القوة)

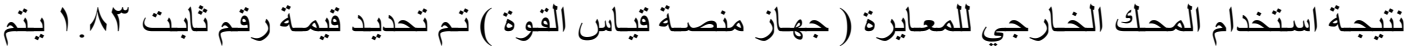

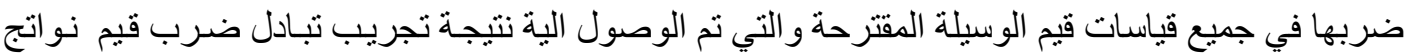

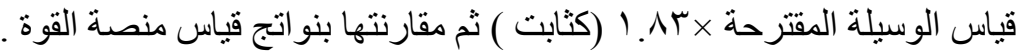

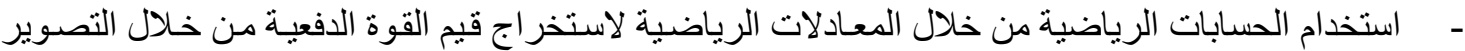

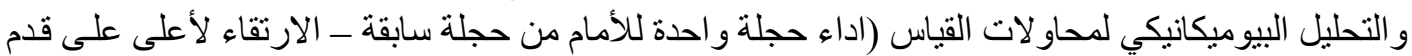

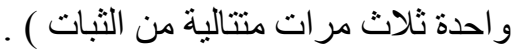

القوة = الكتلة × التعجيل

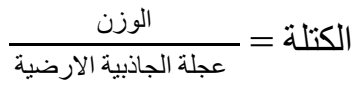

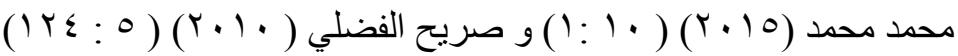


تم استخدام برنامج SPSS الاصدار 17 في استخر اج النتائج الاحصائية حيث تم استخدام المعاملات الاحصـائية الاتية الإية

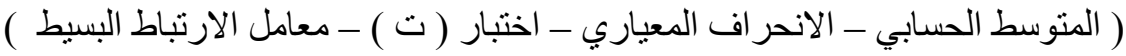

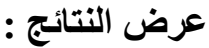

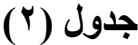

المتوسط الحسابي والانحراف المعياري وقيمة ( ت ) لمتغير قياس أعلى قيم قوى منتجة من الحجلة للأمام بين

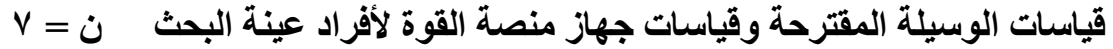

\begin{tabular}{|c|c|c|c|c|c|}
\hline \multirow{2}{*}{ ت } & \multicolumn{2}{|c|}{ جهاز قياس منصة القوة } & \multicolumn{2}{|c|}{ الوسيلة المقترحة } & \multirow{2}{*}{ المتغيرات } \\
\hline & $\varepsilon^{ \pm}$ & س & $\varepsilon^{ \pm}$ & س & \\
\hline$\cdot \pi$ & TYY.TA & $1 K r 9.01$. & rro.019 & $11 r v . \cdot 11$ & قياس أعلى قيم قوى منتجة من الحجلة \\
\hline
\end{tabular}

* معنوي عند مستوى 0.

يتضح من جدول ( r ) انه ليس هناك فروق ذات دلالة معنوية لقيم الحجلة للأمام بين القياسات التي تمت على الوسيلة

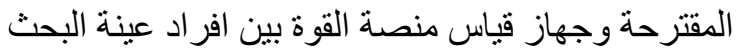

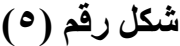

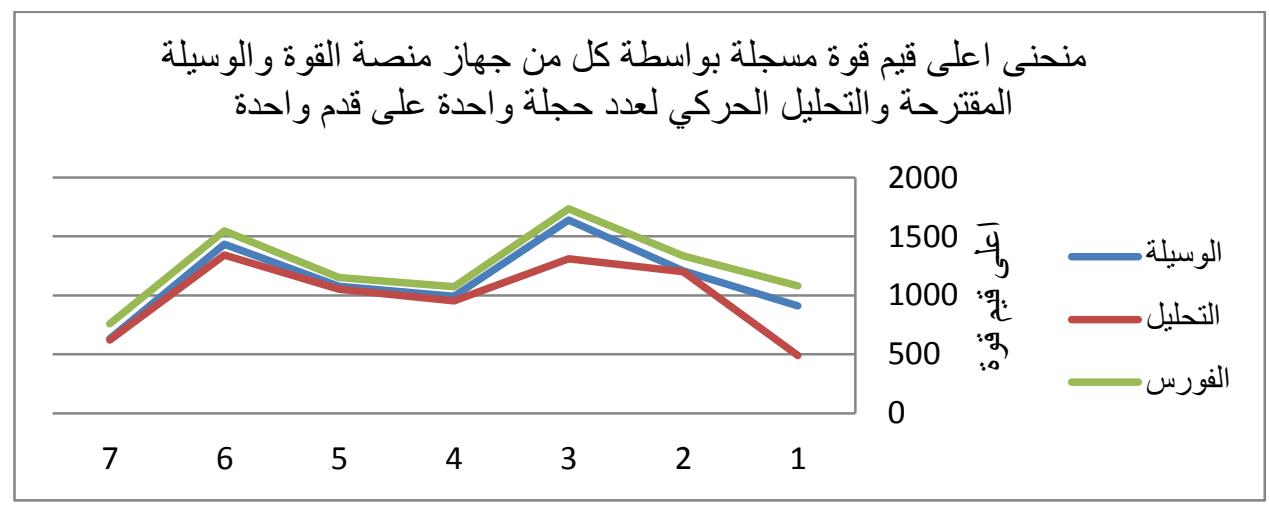

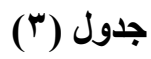

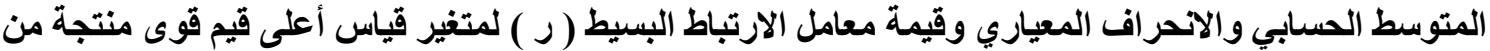
V العجلة للأمام بين قياسات الوسيلة المقترحة وقياسات جهاز منصة القوة لأفراد عينة البحث ل

\begin{tabular}{|c|c|c|c|c|c|}
\hline \multirow[b]{2}{*}{ J } & \multicolumn{2}{|c|}{ جهاز قياس منصة القوة } & \multicolumn{2}{|c|}{ الوسيلة المقترحة } & \multirow{2}{*}{ المتغيرات } \\
\hline & $\varepsilon^{ \pm}$ & س & $\varepsilon^{ \pm}$ & س س & \\
\hline$\cdot .79$ & TrV.rI & $1 r r 9.01$. & rro.019 & $11 r v_{.} \cdot 11$ & قياس أعلى قيمة قوة منتجة من الحجلة \\
\hline
\end{tabular}

يتضح من جدول (ॅ) ان هناك ارتباط منوسط موجب لقياس أعلى قيمة قوة منتجة من الحجلة للأمسام بين قياس الوسيلة المقترحة وقياس جهاز منصة القوة لأفراد عينة البحث. 


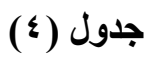

المتوسط الحسابي والانحراف المعياري وقيمة اختبار (ت ) لمتغير قياس أعلى قيم قوى منتجة من الحجلة للأمام V = بين قياسات جهاز قياس منصة القوة وقياسات التحليل الحركي لأفراد عينة البحث

\begin{tabular}{|c|c|c|c|c|c|}
\hline \multirow{2}{*}{ 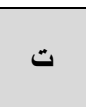 } & \multicolumn{2}{|c|}{ التحليل الحركي } & \multicolumn{2}{|c|}{ جهاز قياس منصة القوة } & \multirow{2}{*}{ المتغيرات } \\
\hline & $\varepsilon^{ \pm}$ & س & $\varepsilon^{ \pm}$ & س & \\
\hline $1 . r \wedge$ & $r T . T V I$ & $99 ะ .9 \vee 9$ & TYY.TA & Krrq.01. & قياس أعلى قيمة قلوة منتجة من الحجلة \\
\hline
\end{tabular}

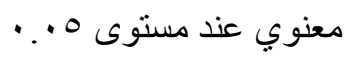

$\longleftarrow *$

يتضح من جدول ( ع ) انه ليس هناك فروق ذات دلالة معنوية لقيم الحجلة للأمسام بين القياسـات التي تمت على جهاز قياس منصة القوة وقياسات التحليل الحركي بين افر اد داد عينة البحث

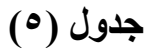

المتوسط الحسابي والانحراف المعياري وقيمة معامل الارتباط البسيط ( ر ) ) لمتغير قياس أعلى قيم قوى منتجة من

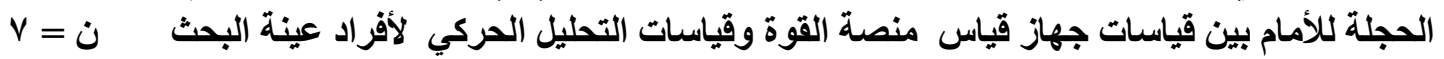

\begin{tabular}{|c|c|c|c|c|c|}
\hline \multirow{2}{*}{ J } & \multicolumn{2}{|c|}{ التحليل الحركي } & \multicolumn{2}{|c|}{ جهاز قياس منصة القوة } & \multirow{2}{*}{ المتغير ات } \\
\hline & $\varepsilon \pm$ & س & $\varepsilon \pm$ & س & \\
\hline . & וערז.וT" & $99 \leq .9 \vee 9$ & TYV.Y人 & 1 Irq.01. & قياس أعلى قيمة قوة منتجة من \\
\hline
\end{tabular}

يتضح من جدول (0) ان هناك ارتباط عالي موجب لقياس أعلى قيمة قوة منتجة من الحجلة للأمام بين قياس جهاز قياس

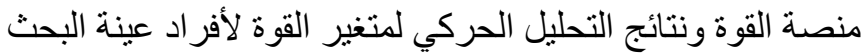

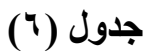

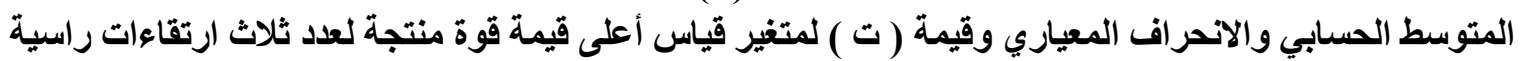
على قام واحدة بين قياسات الوسيلة المقترحة وقياسات جهاز منصة القوة لأفراد عينة البحث

\begin{tabular}{|c|c|c|c|c|c|}
\hline \multirow{2}{*}{ 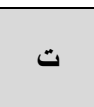 } & \multicolumn{2}{|c|}{ جهاز قياس منصة القوة } & \multicolumn{2}{|c|}{ الوسيلة المقترحة } & \multirow{2}{*}{ المتغيرات } \\
\hline & $\varepsilon^{ \pm}$ & س & $\varepsilon^{ \pm}$ & س & \\
\hline 1.7 & TVT.799 & $\| r \cdot . \wedge \Lambda$ & rAT.0.r & $1 . r 9.1 V A$ & 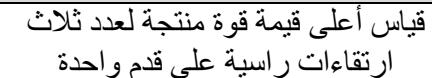 \\
\hline
\end{tabular}

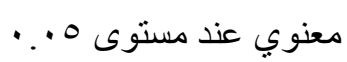

$\longleftarrow$ *

يتضح من جدول ( 7 ) عدم وجود فروق ذات دلالة معنوية لقيم الثلاث ارتقاءات لأعلى بين القياسات التي تمت على التى الوسيلة المقترحة وجهاز قياس منصة القوة بين افر اد عينة البحث

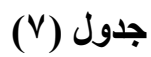

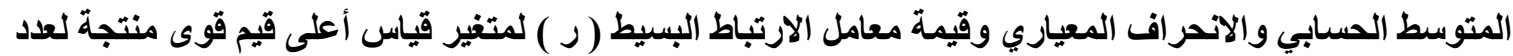

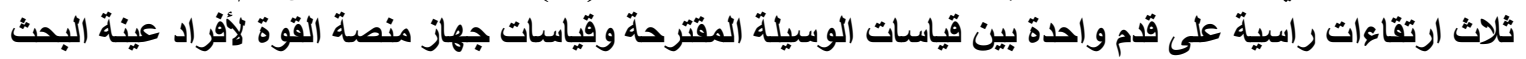

$$
\text { Y }
$$

\begin{tabular}{|c|c|c|c|c|c|}
\hline \multirow{2}{*}{ قيمة (ر) } & \multicolumn{2}{|c|}{ جهاز قياس منصة القوة } & \multicolumn{2}{|c|}{ الوسيلة المقترحة } & \multirow{2}{*}{ المتغيرات } \\
\hline & $\varepsilon^{ \pm}$ & س & $\varepsilon^{ \pm}$ & س & \\
\hline.$\wedge V$ & TVT.79 & $\| \pi \cdot \lambda \Lambda$ & Y人4. & $1 . r 9.1 \mathrm{VA}$ & قياس أعلى قيمة قوة منتجة لعدد ثلاثل \\
\hline
\end{tabular}


يتضح من جدول (V) ان هنالك ارتباط عالي موجب لقياس أعلى قيم قوى ثناث ارتقاءات راسية على قدم واحدة بين قياسات الوسيلة المقترحة وقياسات جهاز منصة القوة لأفر اد عيأ عينة البحث

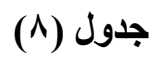

المتوسط الحسابي والانحر اف المعياري وقيمة ( ت ) لمتغير قياس أعلى قيمة قوة منتجة لعدد ثلاث ارتقاعات راسية

\section{على قدم واحدة بين قياسات التحليل الحركي وقياسات جهاز منصة القوة لأفر اد عينة البحث}

\begin{tabular}{|c|c|c|c|c|c|}
\hline \multirow[t]{2}{*}{ ت } & \multicolumn{2}{|c|}{ جهاز قياس منصة القوة } & \multicolumn{2}{|c|}{ التحليل الحركي } & \multirow{2}{*}{ المتغيرات } \\
\hline & $\varepsilon^{ \pm}$ & س - س & $\varepsilon^{ \pm}$ & س - س & \\
\hline $1 . \wedge 1$ & rVT.799 & $\| r \cdot . \wedge 11$ & $r V \leq .979$ & $9 \times 1.07 \leq$ & ياس أعلى قاءت راسية قوة منتجة قدم واحدة ثلاث \\
\hline
\end{tabular}

يتضح من جدول ( ^ ) عدم وجود فروق ذات دلالة معنوية لقيم الثلاث ارتقاءات لأعلى بين القياسـات التي تمت على

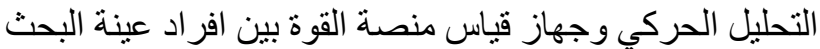

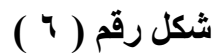

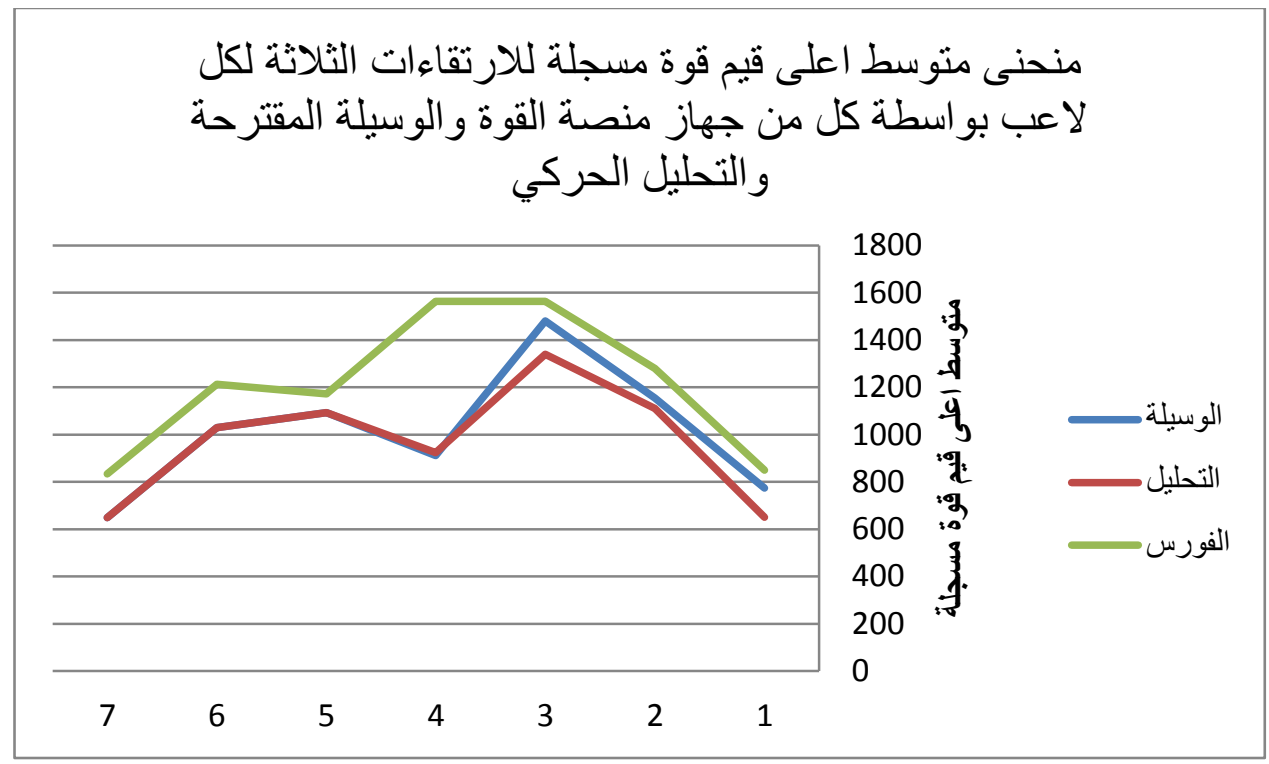

(9) جدول (9)

المتوسط الحسابي والانحراف المعياري وقيمة معامل الارتباط البسيط ( ر ) لمتغير قياس أعلى قيم قوى منتجة لعدد

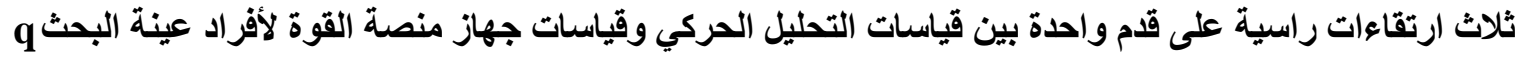

$$
\text { ن }
$$

\begin{tabular}{|c|c|c|c|c|c|}
\hline \multirow{2}{*}{ قيمة (ر) } & \multicolumn{2}{|c|}{ جهاز قياس منصة القوة } & \multicolumn{2}{|c|}{ التحليل الحركي } & \multirow{2}{*}{ المتغيرات } \\
\hline & $\varepsilon^{ \pm}$ & س - س & $\varepsilon^{ \pm}$ & 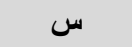 & \\
\hline T & rVT.799 & $\| r \cdot . \wedge 11$ & $r V \leqslant .979$ & $9 \times 1.075$ & قياس أعلى قيمة قوة منتجة لعدد ثلاث إسلاث \\
\hline
\end{tabular}

يتضح من جدول (9) ان هناك ارتباط متوسط موجب لقياس أعلى قيم قوى ثناث ارتقاءات راسية على قدم واحدة بين

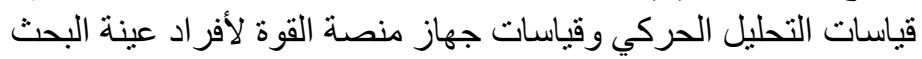


في حال أداء واجب حركه وحيدة نجد ان نتائج جدول (Y) توضح انسه لبس هنـاك فروق ذات دلالـة معنويـة لقيم الحجلـة

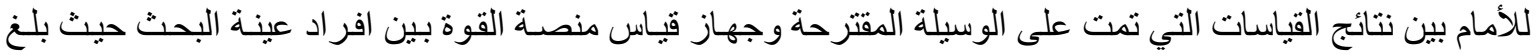

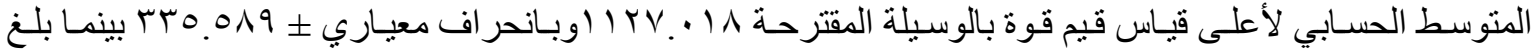

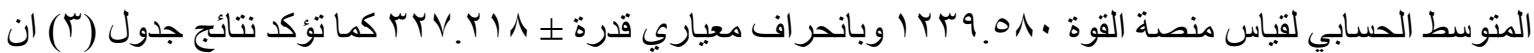

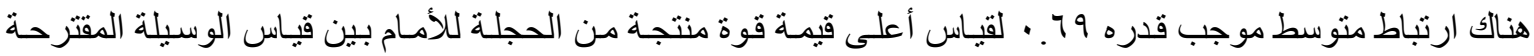

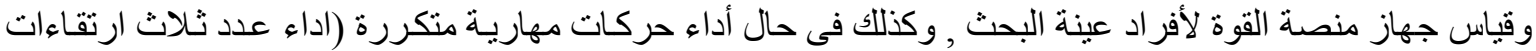

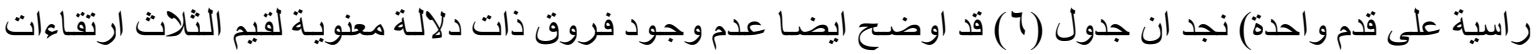

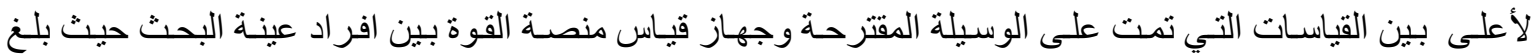

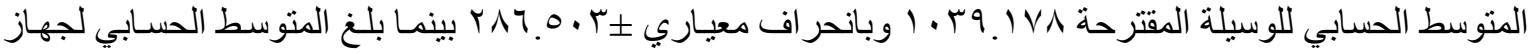

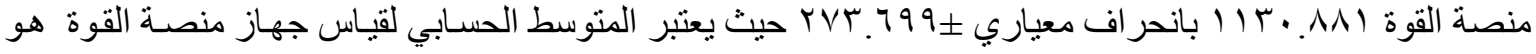

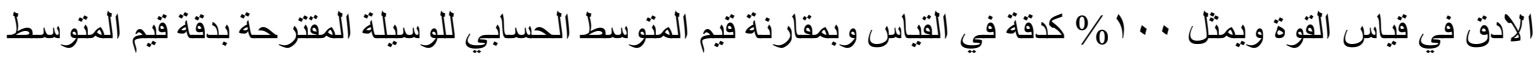

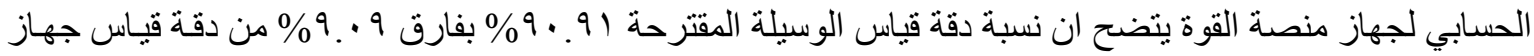

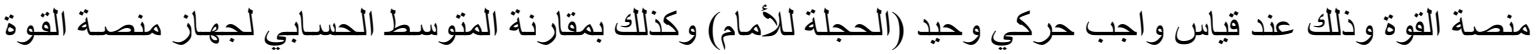
بالمتوسط الحسابي للوسيلة المقترحة عند اداء واجب حركي متكرر (لأداء عدد ثلاث ارتقاءات راسية راسية على قدم و احدة)

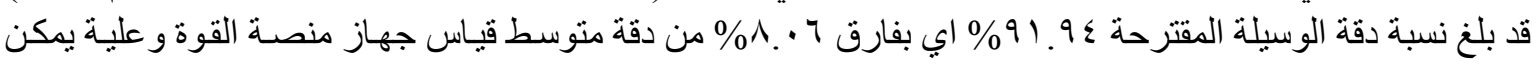

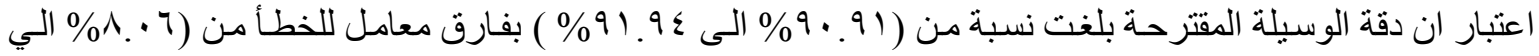

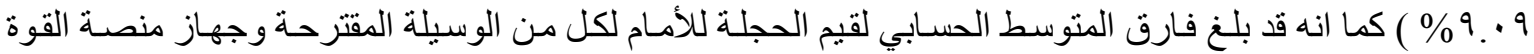

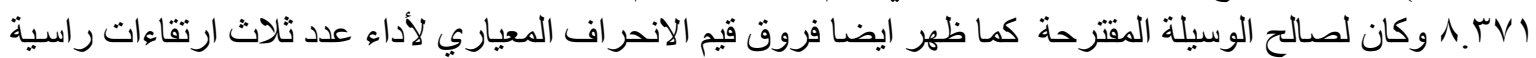

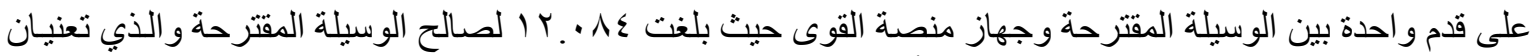

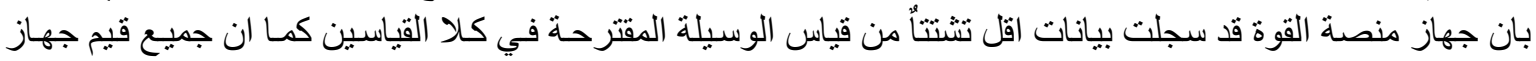

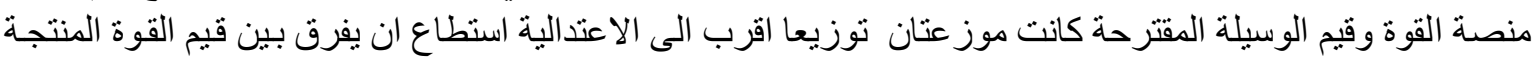

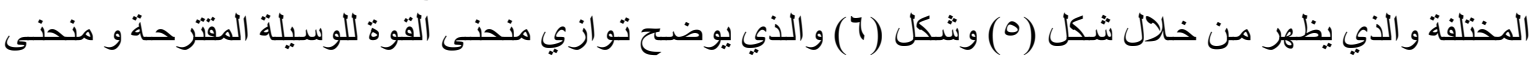

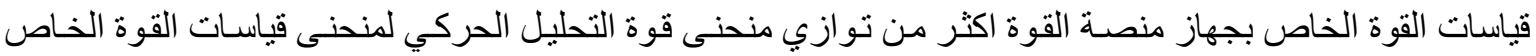

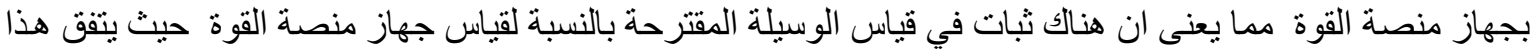

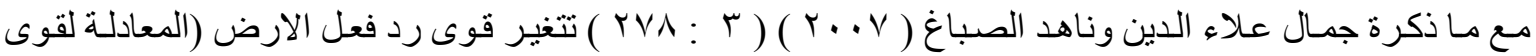

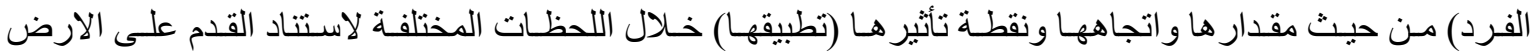

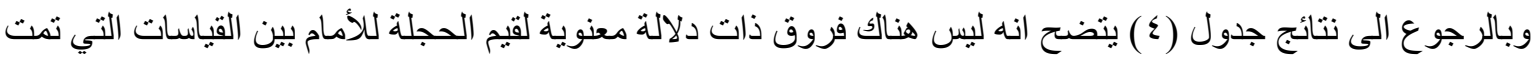

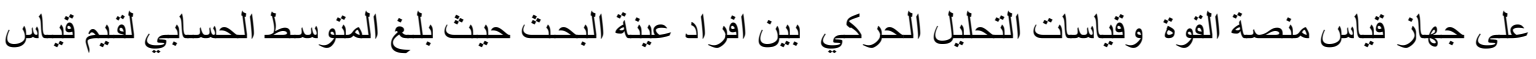

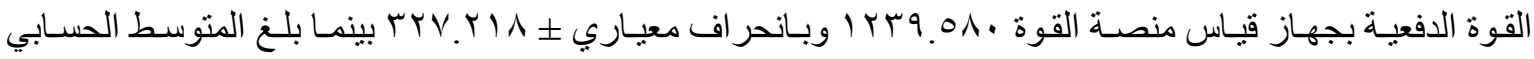

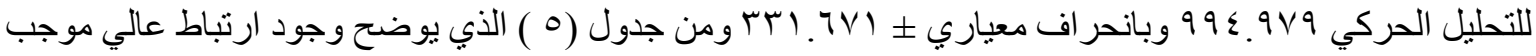

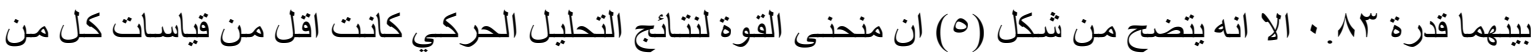

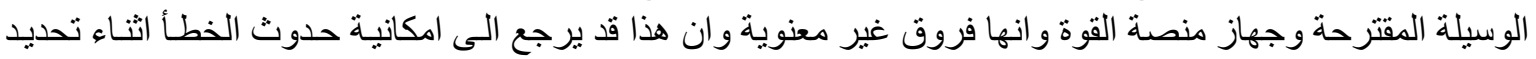

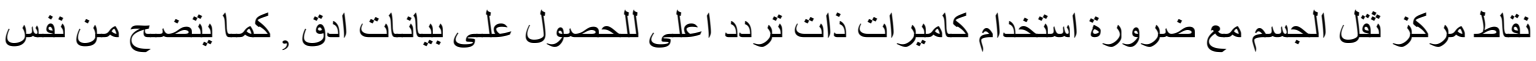

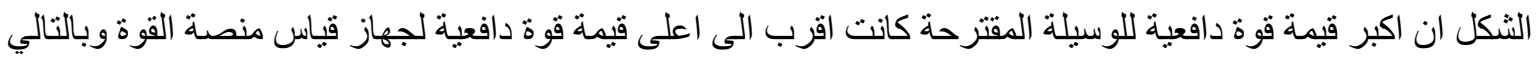

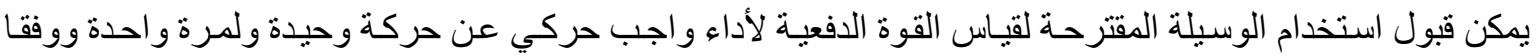
لمتطلبات الاداء الحركي الخاص بذللك. .

كما يتضح من شكل (T) ان منوسط قيم قياسات الوسيلة المقترحة لأعلى قياس قوة قد تطابقت مع متوسط قيم قياسـات

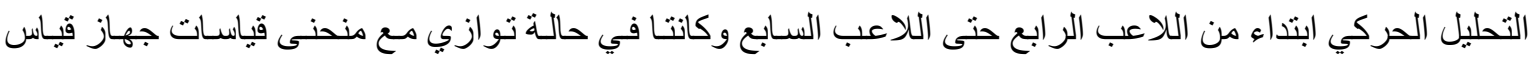


مذصة القوة مما يدل ذلك على ان هناك قوة ارتباط بين نتائج قياس الوسيلة المقترحة بنتائج قياس جهاز منصـة القوة

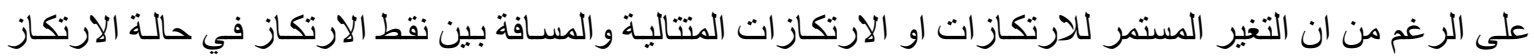

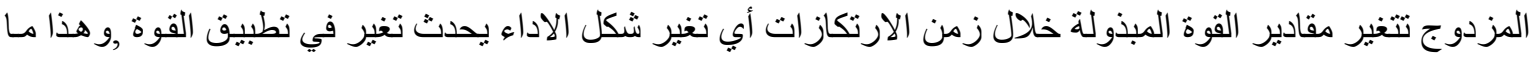

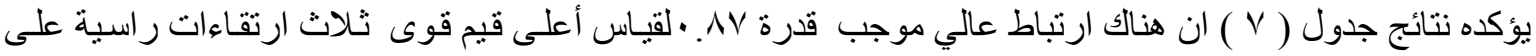

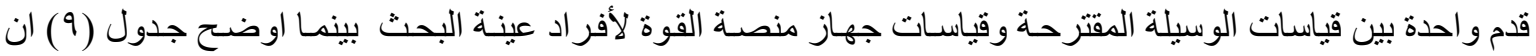

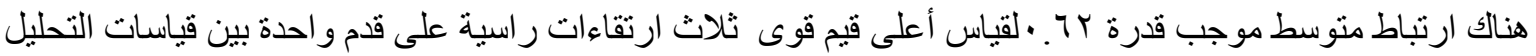

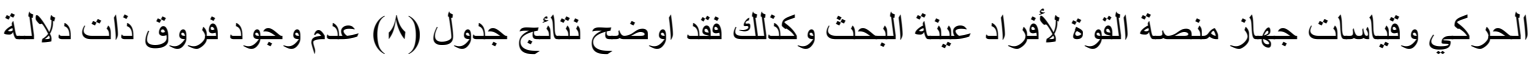
معنوية لقيم الثناث ارتقاءات لأعلى بين القياسات التي تمت بالتحليل الحركي وجهاز قياس منصة القوة بين افر اد عينة البحث.

ومن خلال ما تم عرضة فانة يمكن قبول الوسيلة المقترحة لقياس القوة الدفعية لأداء مهاري واحد (واجب حركي حركي عن

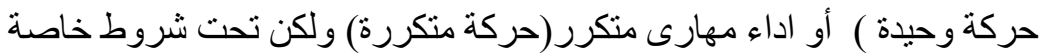

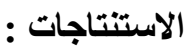

\section{في ضوء طبيعة البحث وحدود عينة تم استتتاج الأتية :}

ا ـ. قبول استخدام الوسيلة المقترحة وفق شروط استبدال حساسات القوة وفق وزن الافر اد المستخدمين للوسيلة .

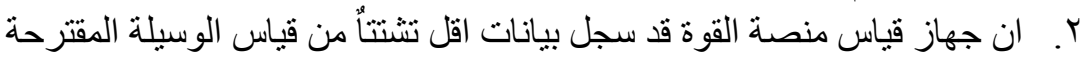

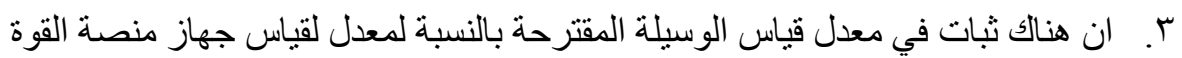

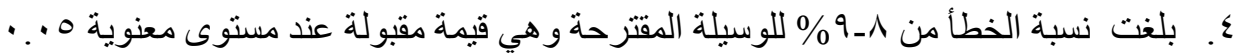

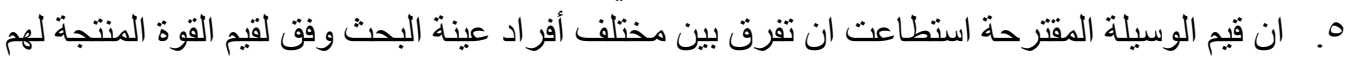
7. نتيجة استخدام الوسيلة المقترحة ستمكن المدربين من الحصول على معلى ملومات فورية عن طبيعة الاداء الفعلي

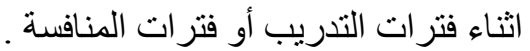

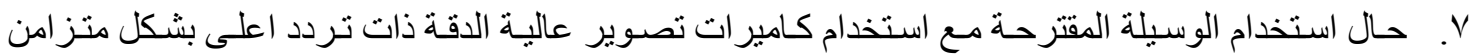

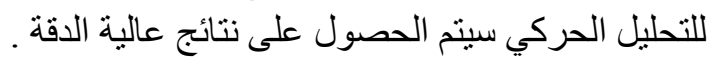
^. يمكن استخدام الوسيلة المقترحة داخل الملاعب المفتوحة دون التقبد بمساحة أو التأثير على الاداءات الحركية.

\section{في ضوع نتائج وطبيعة البحث يوصي الباحث بالاتي :}

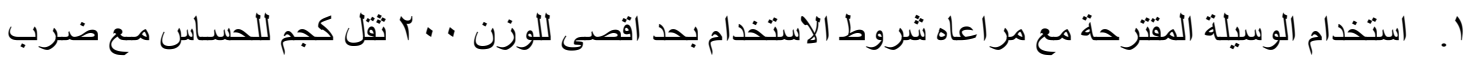

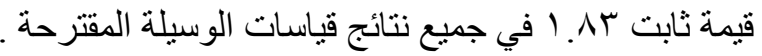

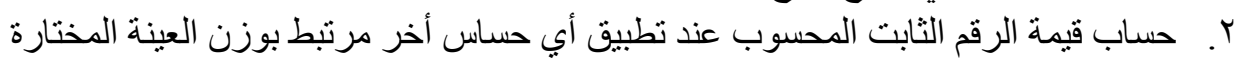

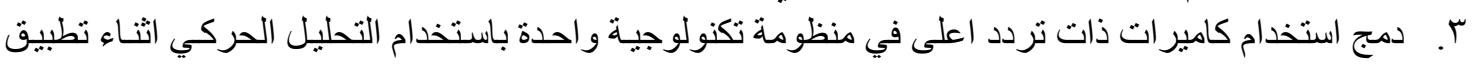
القياس وبشكل متز امن .

ع. استخدام الوسيلة المقترحة أو مثيلتها لتقنين الاحمال البدنية . ๑. اجر اء مزيد من الدر اسات و الابحاث حول تطوير وسائل قياس القوة الدفعية . 


\section{أولاً :المراجع العربية:}

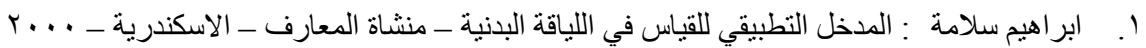

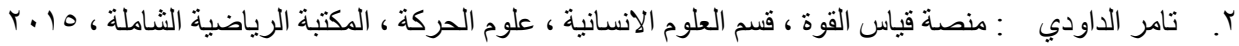

http://www.sport.ta4a.us/human-sciences/movement-science/1240-force-plateform.html www.sport.ta4a.net

r.جمال علاء الدين ـ ناهد الصباغ :الاسس المترولوجية لتقديم مستوى الاداء البدني و المهاري و الخططي للرياضيين ، منشاة

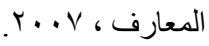

ع. صريح الفضلي قياس القوة و القدرات الانفجارية و السريعة على وفق متغير ات الكتلة و السر عة و قياس منصة القوة ,

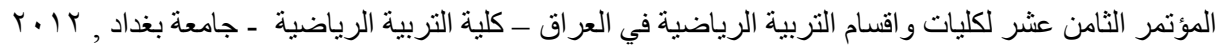

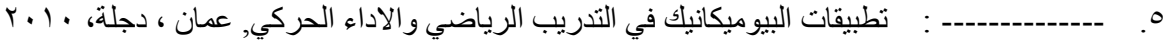

7. عدي حسن التحليل البيوميكانيكي للمهارات الرياضية , الاكآديمية الرياضية العر اقية الاكترونية ,

r.. ${ }^{\top}$ www.iraqacad.org

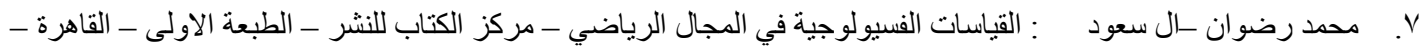

A. محمد شحاتة ـ محمد بريقع : دليل القياسات الجسية واختبار ات الاداء الحركي ـ منشاة المعارف اسكندرية ـ 1990

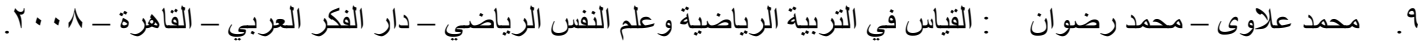

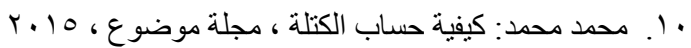

http://mawdoo3.com/\%D9\%83\%D9\%8A\%D9\%81\%D9\%8A\%D8\%A9_\%D8\%AD\%D8\%B3\%D8\%A7

\%D8\%A8_\%D8\%A7\%D9\%84\%D9\%83\%D8\%AA\%D9\%84\%D8\%A9

$$
\text { l' }
$$

http://www.ibtesama.com/vb/showthread-t_28063.html

Powered by vBulletin® Copyright $@ 2000$ - 2015, Jelsoft Enterprises Ltd .

SEO by vBSEO 3.6.0 PL

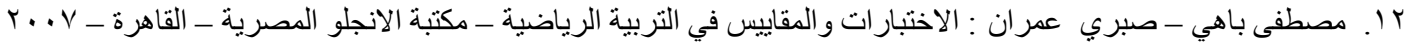




\section{الملخص باللغة العربيـة}

تصميم وسيلة مقترحة لقياس القوة الد فعية

محمد على عبد المجيد المقطف

قسم تدريب مسابقات الميدان و المضماركلية التربية الرياضية للبنين - جامعة الإسكندرية ـ جمهورية مصر العربية.

تهدف هذه الدر اسـة للتعرف على امكانيـة تصميم و استخدام وسيلة مقترحة لقياس القوة الدفعيـة النهائية للرجلين كقيساس مباثر باستخدام منحنى القوة مع الزمن اثناء تتفيذ الاداءات المهاريـة المختلفة وذللك من خـلال تطبيق المعايرة الخارجية للتقنين علمي لوسيلة القياس المقترحة ومدي قبول نتائجها ، طبقت خطو ات التقنين على عينة قو امها V ناشئين تحت با ا سنة وكانت اهم النتائج تؤكد امكانية و سلامة الوسيلة المقترحة لقياس القوة الدفعية النهائية المنتجة للرجلين حيث يتضح ذلك من خلال عدم وجود الفروق ذات الدلالة المعنوية بين نتائج قياس القوة المنتجة بالوسيلة المقترحـة و جهاز منصـة القوة و التحليل الحركي باستخدام القوانين الميكانيكية. 
